Article

\title{
A Room Temperature Nitric Oxide Gas Sensor Based on a Copper-Ion-Doped Polyaniline/Tungsten Oxide Nanocomposite
}

\author{
Shih-Han Wang ${ }^{1}$, Chi-Yen Shen ${ }^{2, *}$, Jian-Ming Su ${ }^{2}$ and Shiang-Wen Chang ${ }^{1}$ \\ 1 Department of Chemical Engineering, I-Shou University, Kaohsiung 84001, Taiwan; \\ E-Mails: shwang@isu.edu.tw (S.-H.W.); y10171019@yahoo.com.tw (S.-W.C.) \\ 2 Department of Electrical Engineering, I-Shou University, Kaohsiung 84001, Taiwan; \\ E-Mail: z560327@yahoo.com.tw \\ * Author to whom correspondence should be addressed; E-Mail: cyshen@isu.edu.tw; \\ Tel.: +886-7-657-7711 (ext. 2651).
}

Academic Editor: Gerhard Lindner

Received: 5 December 2014 / Accepted: 16 March 2015 / Published: 24 March 2015

\begin{abstract}
The parts-per-billion-level nitric oxide (NO) gas sensing capability of a copper-ion-doped polyaniline/tungsten oxide nanocomposite $\left(\mathrm{Cu}^{2+} / \mathrm{PANI} / \mathrm{WO}_{3}\right)$ film coated on a Rayleigh surface acoustic wave device was investigated. The sensor developed in this study was sensitive to NO gas at room temperature in dry nitrogen. The surface morphology, dopant distribution, and electric properties were characterized using scanning electron microscopy, energy-dispersive X-ray spectroscopy mapping, and Hall effect measurements, respectively. The $\mathrm{Cu}^{2+} / \mathrm{PANI} / \mathrm{WO}_{3}$ film exhibited high $\mathrm{NO}$ gas sensitivity and selectivity as well as long-term stability. At $1 \mathrm{ppb}$ of NO, a signal with a frequency shift of $4.3 \mathrm{ppm}$ and a signal-to-noise ratio of 17 was observed. The sensor exhibited distinct selectivity toward $\mathrm{NO}$ gas with no substantial response to $\mathrm{O}_{2}, \mathrm{NH}_{3}$ and $\mathrm{CO}_{2}$ gases.
\end{abstract}

Keywords: copper-ion-doped polyaniline/tungsten oxide nanocomposite; nitric oxide (NO); gas sensor; Rayleigh surface acoustic wave (SAW)

\section{Introduction}

The demand for highly sensitive sensors featuring selectivity toward specific gases in various applications, such as industrial process control, environment protection, food safety, healthcare, and 
security, has increased. Several sensing technologies, including optical, electronic, and electrochemical methods, have been developed for use in various applications [1-3]. Nitric oxide (NO) emissions are mainly generated through the combustion of fossil fuels, and combustion that occurs in power plants and vehicle engines. NO sensors are required to differentiate NO from other combustion gases in aftertreatment systems of the waste [4]. In environmental monitoring, NO sensors operate at sub-parts-per-million levels.

NO sensors are also required for diagnosing respiratory diseases because the NO concentration in exhaled breath can indicate inflammation of the airways [5]. Studies have reported that an increased NO concentration in exhaled air is a key symptom of asthma [6-8]. Regarding breath analysis, sensors must be able to detect NO concentrations in the parts-per-billion range. The most common device applied in breath monitoring is the bulky chemiluminescence analyzer [9]. A sensor array based on a yttria-stabilized zirconia (YSZ) electrolyte and containing a $\mathrm{WO}_{3}$ sensing electrode and Pt-zeolite/Pt as the reference electrode designed for parts-per-billion-level NO detection was developed [10] and tested in a temperature range of 400-600 ${ }^{\circ} \mathrm{C}$. An NO-selective sensor based on mixtures of $\mathrm{WO}_{3}$ and $\mathrm{Cr}_{2} \mathrm{O}_{3}$ was designed for operation at a low parts-per-billion level and was operated at $300{ }^{\circ} \mathrm{C}[11]$.

As mentioned previously, metal oxides are effective materials applied in parts-per-billion-level NO detection. Among these materials, $\mathrm{WO}_{3}, \mathrm{ZnO}$, and $\mathrm{SnO}_{2}$ are often applied in $\mathrm{NO}_{\mathbf{x}}$ sensing [2,12-14]. However, such sensors must be operated at a high temperature, typically above $200{ }^{\circ} \mathrm{C}$. In addition, metal-oxide-based gas sensors exhibit several disadvantages including poor selectivity, response, and recovery times in the range of minutes or even hours as well as high power consumption. In a previous study, we combined a conducting polymer, polyaniline (PANI), and a metal oxide, $\mathrm{PANI} / \mathrm{WO}_{3}$ [15], to improve the sensitivity of detection at room temperature and retain the advantages of the constituent parts, which feature high surface functions to chemisorption for gas detection. Nevertheless, the detection limit for the NO gas was $23 \mathrm{ppb}$, which is insufficient for certain biomedical applications. To increase the sensitivity and lower the detection limit, selective reductive catalysts were introduced. Numerous transition metals, such as $\mathrm{Fe}, \mathrm{V}, \mathrm{Cr}$, and $\mathrm{Cu}$, exhibit low-temperature catalytic activity [16], and copper is among the most typical catalysts applied in selective catalytic reduction reactions.

This study focused on $\mathrm{Cu}^{2+} / \mathrm{PANI} / \mathrm{WO}_{3}$-nanocomposite-coated surface acoustic wave (SAW) sensors featuring sensitivity and selectivity toward NO in the parts-per-billion range at room temperature in dry nitrogen. The advantages of SAW devices, such as a small size, fabrication reproducibility, and fast output, make them suitable for application in gas detection [17-19]. SAW sensors can respond to targets that contribute to perturbation in SAW wave propagation. Mass loading, the electric effect, and the acoustoelectric effect perturb SAW propagation while the SAW sensor detects the target gas. The change in SAW propagation can be evaluated by measuring the frequency shift and resistance change of the SAWs. Therefore, this study investigated the detection properties of a sensor by analyzing SAW responses.

\section{Experimental Section}

\subsection{Materials and Reagents}

An aniline monomer was purchased from ACROS (Bergen County, NJ, USA) and was distilled prior to use. Tungsten hexachloride (WCl6, Aldrich, St Paul, MN, USA), ammonium persulphate 
$\left(\left(\mathrm{NH}_{4}\right)_{2} \mathrm{~S}_{2} \mathrm{O}_{8}\right.$, Showa, Tokyo, Japan), hydrogen chloride (HCl, Union Chemical Works Ltd., Hsinchu, Taiwan), isopropanol (TEDIA, Fairfield, $\mathrm{OH}, \mathrm{USA}$ ), copper sulfate ( $\mathrm{CuSO}_{4}$, Aldrich), and ammonium hydroxide $\left(\mathrm{NH}_{4} \mathrm{OH}\right.$, TEDIA, Fairfield, $\left.\mathrm{OH}, \mathrm{USA}\right)$ were used without treatment. All chemicals used were of analytical reagent grade.

\subsection{Preparation of $\mathrm{Cu}^{2+} / \mathrm{PANI} / \mathrm{WO}_{3}$ Films}

The procedure used to produce the tungsten oxide and tin oxide/PANI solutions was similar to that employed in our previous studies [20-22]. Tungsten oxide gel was first synthesized and then mixed with an aniline precursor. Subsequently, tungsten (VI) hexachloride (3 g) was mixed with isopropanol $(50 \mathrm{~mL})$ in an ice bath. Hydrolysis was achieved by adding a $0.5 \mathrm{M} \mathrm{NH} 4 \mathrm{OH}$ aqueous solution $(5 \mathrm{~mL})$ at room temperature. The chloride ion in the solution was removed using deionized water. The precipitate was peptized by slowly applying $\mathrm{NH}_{4} \mathrm{OH}$ and refluxed for 3 days until it become gel. Distilled aniline $(0.1 \mathrm{~mol})$ was dissolved in $1 \mathrm{M} \mathrm{HCl}$ and mixed with a tungsten oxide gel through vigorous stirring. An ammonium persulphate solution $(0.1 \mathrm{M})$ was added dropwise into the thoroughly mixed solution and polymerization proceeded at an ambient temperature for $20 \mathrm{~h}$. Subsequently, the obtained $\mathrm{PANI} / \mathrm{WO}_{3}$ precipitate was rinsed using deionized water and then washed with a $1 \mathrm{M} \mathrm{HCl}$ solution. The obtained solution was diluted using i-propanol to facilitate thin film deposition.

The obtained $\mathrm{PANI} / \mathrm{WO}_{3}$ solution was mixed with a $\mathrm{CuSO}_{4}$ aqueous solution to form a 0.05 wt \% copper-ion-doped $\left(\mathrm{Cu}^{2+}\right) \mathrm{PANI} / \mathrm{WO}_{3}$ film. The surface morphology and distribution of the elements were characterized using a field-emission scanning electron microscope (FE-SEM, Hitachi 4700, Toronto, Canada) and energy-dispersive X-ray spectroscopy (EDS) mapping (Horiba, Kyoto, Japan). The electric properties of the sensing film were evaluated using a Hall effect measurement system (HMS-3000, Ecopia, Chandler Heights, AZ, USA).

\subsection{Fabrication of Surface Acoustic Wave Sensors}

The SAW sensor was designed as a two-port resonator and was fabricated on a ST-cut quartz substrate. ST-cut quartz exhibits high temperature stability at room temperature [23-25]. Aluminum (Al) interdigital transducers (IDTs) were produced by conducting radio-frequency sputtering by using the lift-off method and exhibited a thickness of $3200 \AA$. The IDTs exhibited a pair number of 104, a period $p$ of $32 \mu \mathrm{m}$, and an aperture of $960 \mu \mathrm{m}$. Each reflector in the device had $150 \mathrm{Al}$ strip gratings; the metallization ratio was 0.5 , and the length of the cavity was $605 \mu \mathrm{m}$. The oscillation frequency was measured by the spectrum analyzer (4395A, Agilent, Santa Clara, CA, USA) and was stable at $98.47 \mathrm{MHz}$ after SAW resonator was connected with the oscillator [20]. The $\mathrm{Cu}^{2+} / \mathrm{PANI} / \mathrm{WO}_{3}$ sensitive layer was spin coated on the space between the input and output IDTs and covered an area of $1.5 \times 0.5 \mathrm{~mm}^{2}$. The thickness of the sensitive layer was approximately $3000 \AA$ measured by ellipsometry.

\subsection{Surface Acoustic Wave Sensor Measurement}

This study made use of a dual-device configuration shown in Figure 1 to reduce interference from the environment. A coated SAW resonator was used as a sensor, and a non-coated resonator was used as a reference. The dimensions of each device were $15.4 \times 5.8 \times 0.5 \mathrm{~mm}^{3}$. Figure 2 shows the setup 
applied in NO gas measurement experiments. High-purity nitrogen gas and certified $116 \mathrm{ppb}$ and $300 \mathrm{ppb}$ NO gas (Jing-De Gas Co., Kaohsiung, Taiwan) were mixed in various ratios by using a commercial gas mixer (Jing-De Gas Co.). Various concentrations of NO flowed from the gas mixer. The outflow, which was adjusted using mass flow controllers (Sierra, Kyoto, Japan), exhibited a constant flow rate of $110 \mathrm{~mL} / \mathrm{min}$. The NO breath sensor (FENO, Bedfont, UK) is an independent analytical instrument to analyze NO gas concentration generated by the gas mixer. The dual-device sensing system was placed in a temperature-stabilized, sealed $5-\mathrm{cm}^{3}$ test chamber. A temperature controller maintained a constant temperature of $23{ }^{\circ} \mathrm{C}$. The performance of the fabricated SAW sensor was measured at various concentrations of $\mathrm{NO}$ gas in the closed test chamber.

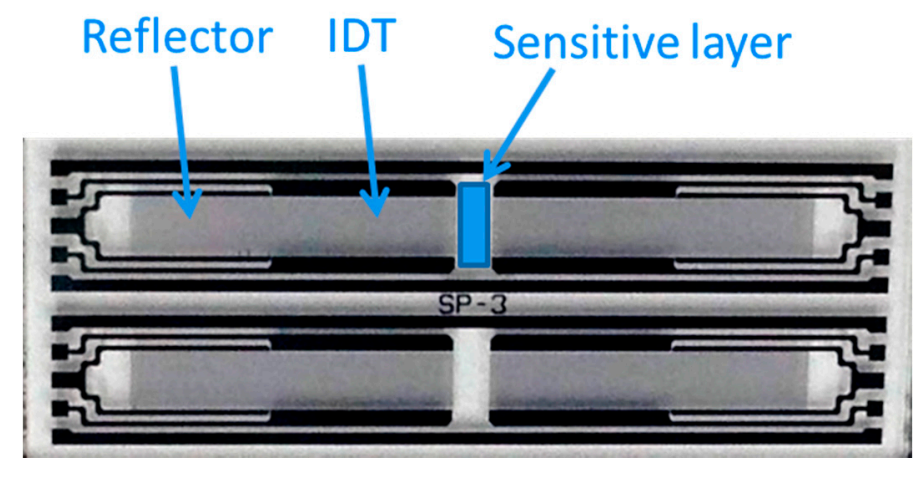

Figure 1. Photograph of a dual-device configuration.

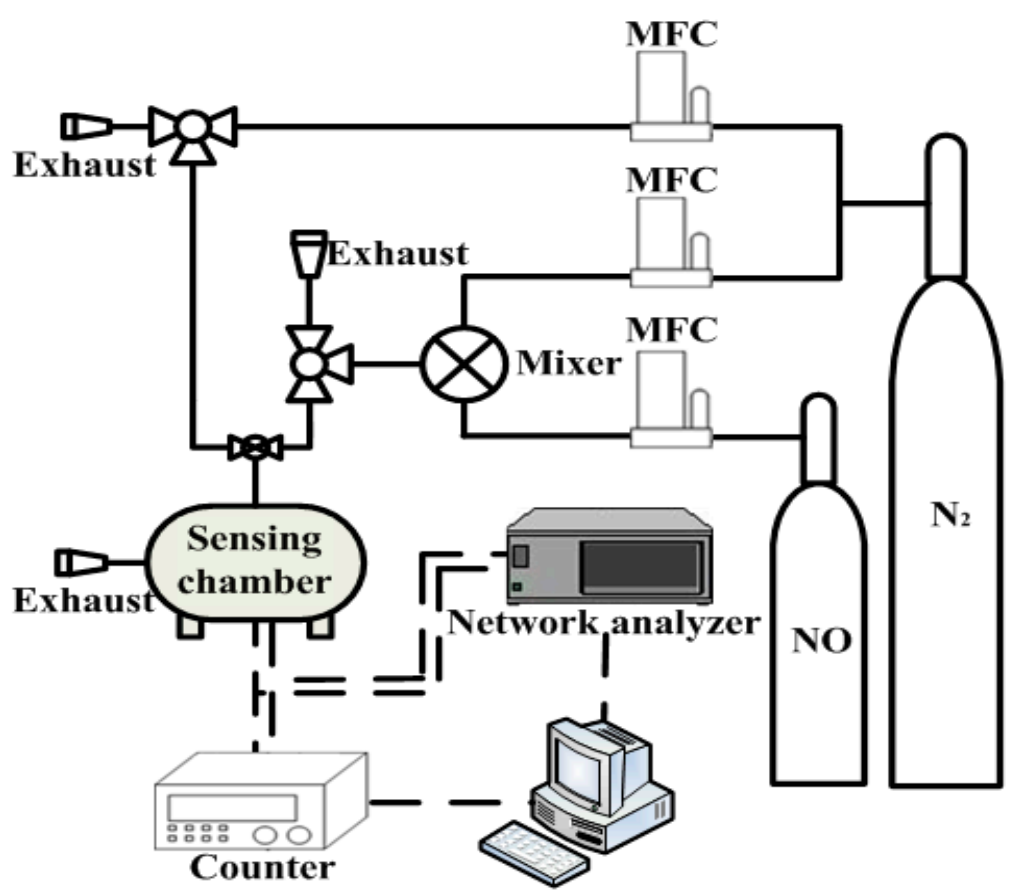

Figure 2. Experimental setup for measuring NO gas.

Two electronic configurations [26] for characterizing the SAW sensor were used in this study. One is the feedback-loop oscillator design [27] which was applied to design the SAW resonator stabilized oscillators to provide a single-frequency signal, measured by a frequency counter (53132A, Agilent, Santa Clara, CA, USA). The other one is a network analyzer (E5061B, Agilent), with software 
(ATeam Scientific Ltd., Hsinchu, Taiwan), connected to the SAW resonator to obtain the impedance characteristics of the sensor. A frequency counter and a network analyzer were connected to a computer system by using a GPIB interface board and used to record the responses of the sensor. The impedance measurement was carried out at the resonant frequency in this study. Noise measurement was conducted using data collected for $5 \mathrm{~min}$ at 20 points per minute, and noise was employed as the standard deviation of the residuals of the linear least squares fit through the data.

\section{Results and Discussion}

The operating frequency of the SAW resonator was measured before and after the $\mathrm{Cu}^{2+} / \mathrm{PANI}^{2} / \mathrm{WO}_{3}$ sensitive layer was deposited and the frequencies were $98.392 \mathrm{MHz}$ and $98.243 \mathrm{MHz}$, respectively, as shown in Figure 3. This negative frequency shift was accompanied by an increase in attenuation caused by mass loading on the SAW device. The same coating was applied to three sensors. The difference in the frequency shift between the sensors was less than $2 \%$, indicating that the deposition method was reproducible.

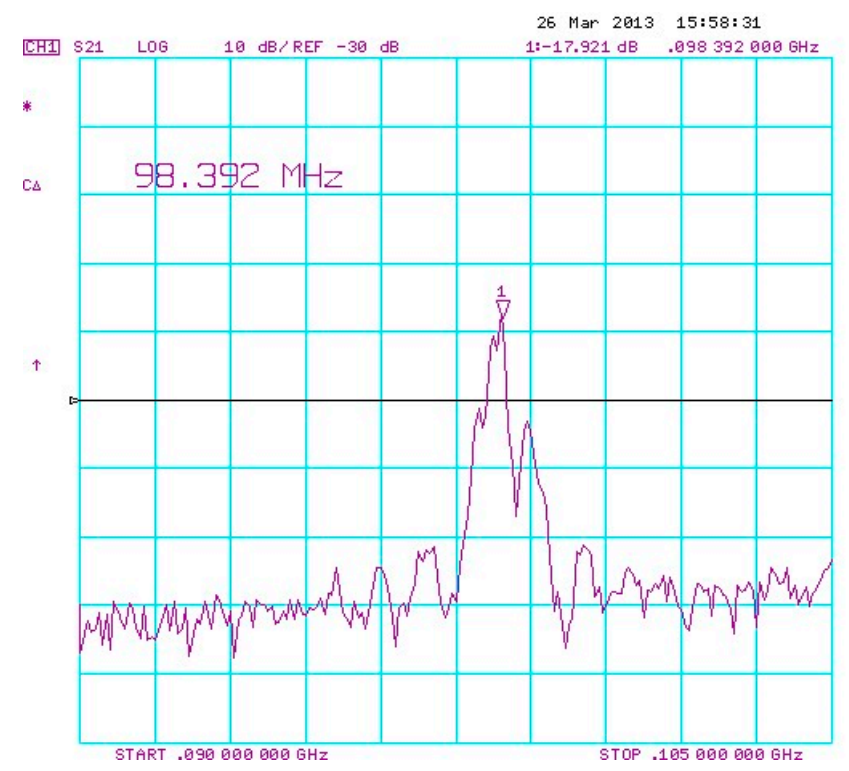

(a)

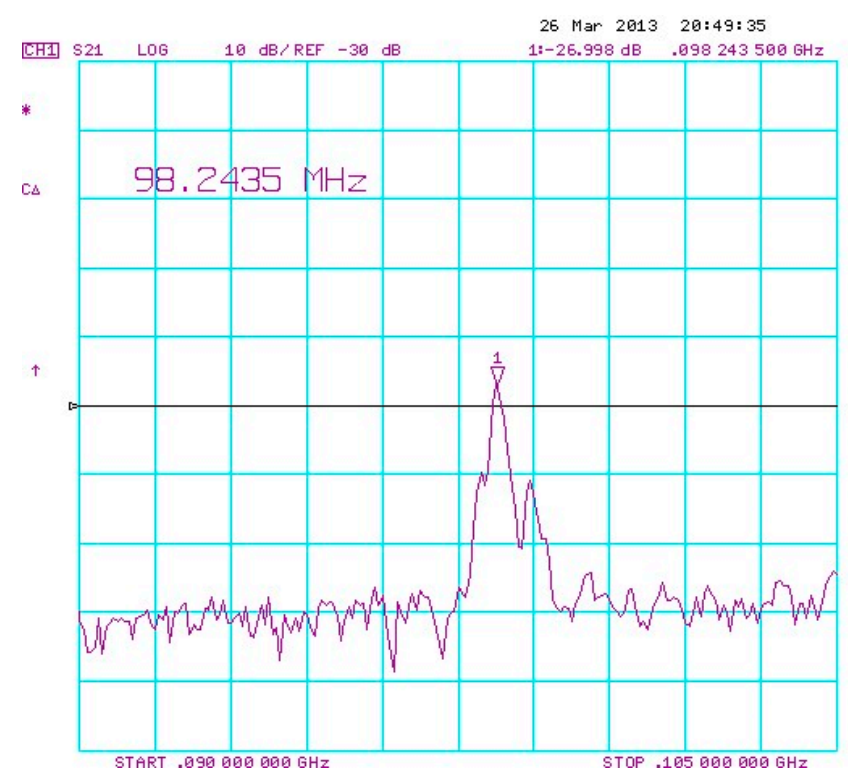

(b)

Figure 3. Example of frequency responses of (a) a raw SAW resonator and (b) after $\mathrm{Cu}^{2+} / \mathrm{PANI} / \mathrm{WO}_{3}$ layer coating.

The surface morphology of the as-synthesized sensitive film was analyzed using a FE-SEM and the distribution of various elements was characterized using EDS mapping as shown in Figure 4a,b, respectively. Figure $4 \mathrm{a}$ shows that the sensitive layer exhibited a uniform and porous structure that provided a large surface area for gas sensing. In Figure $4 b$, the bright dots indicate the distribution of various elements. $\mathrm{W}$ and $\mathrm{Cu}$ mapping of the $\mathrm{Cu}^{2+} / \mathrm{PANI} / \mathrm{WO}_{3}$ sensitive layer indicated that the tungsten oxide and copper ions were distributed in the network of PANI uniformly, constituting a porous and thin film. 


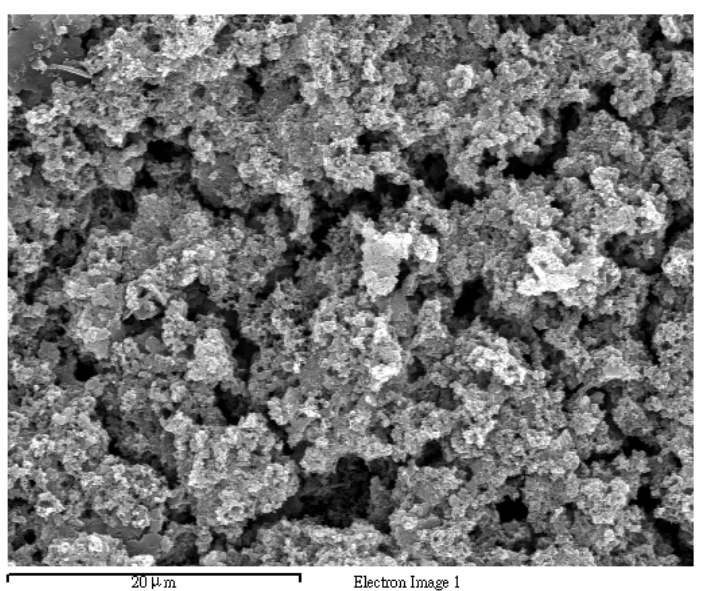

(a)
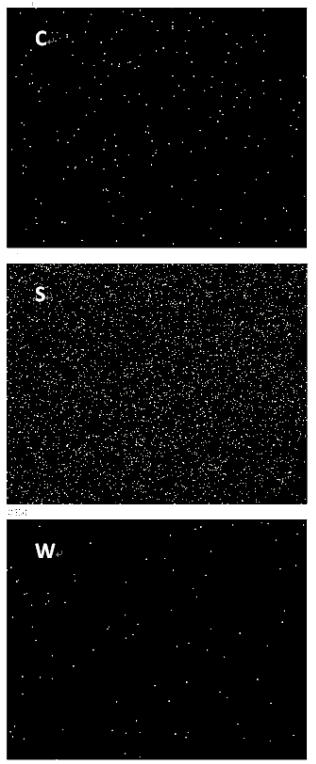

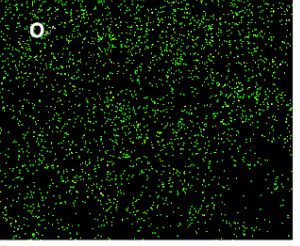

cu

(b)

Figure 4. (a) SEM image of the as-synthesized sensitive layer and (b) the EDS mapping of various elements.

The NO sensing properties in dry nitrogen were tested and the changes in frequency and resistance as a function of time were recorded when the sensor was exposed to NO gas at different concentrations. Figure 5 shows the transient response of a SAW sensor coated with a $\mathrm{Cu}^{2+} / \mathrm{PANI}^{2} / \mathrm{WO}_{3}$ sensitive layer at various NO concentrations ranging from low to high. The response was calculated as $\Delta \mathrm{f} / \mathrm{f}_{\mathrm{o}}=\left(\mathrm{f}-\mathrm{f}_{\mathrm{o}}\right) / \mathrm{f}_{\mathrm{o}}$, where $\mathrm{f}$ is the resonant frequency of the sensor in the presence of NO and $\mathrm{f}_{\mathrm{o}}$ is the initial resonant frequency of the sensor in dry nitrogen. Only dry nitrogen flowed through the test chamber before $\mathrm{NO}$ was released. After the SAW sensor coated with a $\mathrm{Cu}^{2+} / \mathrm{PANI} / \mathrm{WO}_{3}$ sensitive layer was exposed to NO, it detected an increased frequency. After $180 \mathrm{~s}$, NO flow was discontinued and only dry nitrogen flowed through the test chamber to enable the frequency to return to its original level. The SAW sensor coated with a $\mathrm{Cu}^{2+} / \mathrm{PANI} / \mathrm{WO}_{3}$ sensitive layer exhibited a change in frequency of more than $9.6 \mathrm{ppm}$ when it was exposed to $\mathrm{NO}$ at $40 \mathrm{ppb}$. These results indicated that an SAW sensor coated with a $\mathrm{Cu}^{2+} / \mathrm{PANI} / \mathrm{WO}_{3}$ sensitive layer was able to reversibly detect parts-per-billion levels of $\mathrm{NO}$ at room temperature.

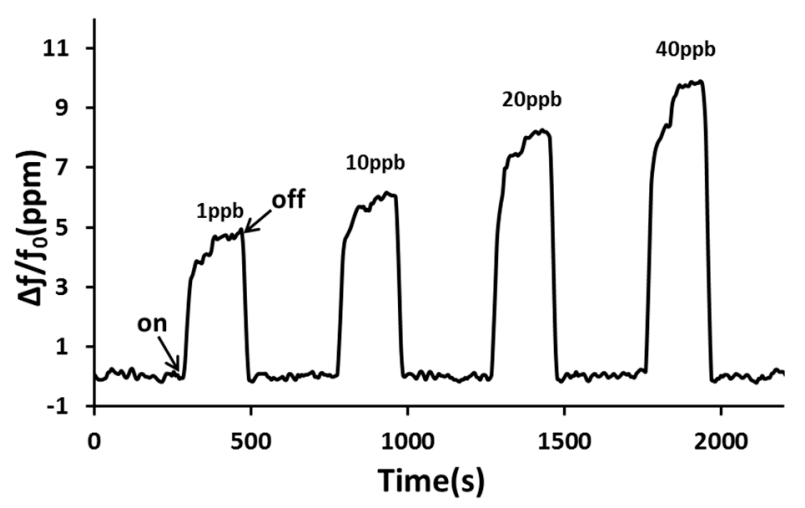

Figure 5. The transient response of a sensor to NO at various concentrations using dry nitrogen as carrier gas at room temperature. 
The frequency shift shown in Figure 5 gives a positive frequency shift during exposure to NO gas. This phenomenon can be explained by the perturbation mechanisms in Equation (1). The perturbation mechanisms of SAW propagation after absorbing gas targets can be expressed as [28,29]:

$$
\frac{\Delta f}{f_{O}} \cong \frac{\Delta v}{v_{O}}=-c_{m} f_{O} \Delta\left(\frac{m}{A}\right)+4 c_{e} f_{O} \Delta\left(h G^{\prime}\right)-\frac{K^{2}}{2}\left(\frac{1}{1+v_{O}^{2} \Delta\left(\frac{C_{S}}{\sigma_{S}}\right)^{2}}\right)
$$

where $c_{\mathrm{m}}$ and $c_{\mathrm{e}}$ are the coefficients of mass sensitivity and elasticity, $m / A$ is the change in mass per unit area, $h$ is thickness of the sensitive layer, $\mathrm{G}^{\prime}$ is the shear modulus, $K^{2}$ is the electromechanical coupling coefficient, $\sigma_{\mathrm{s}}$ is the sheet conductivity of the sensitive layer, $\mathrm{C}_{\mathrm{s}}$ is the capacitance per unit length of the SAW substrate. The first term in Equation (1) represents the mass-loading effect, which results in a function of gas concentration. The second term is contributed from elastic properties of the sensitive layer. The third term represents the acoustoelectric effect. The frequency shift due to the change of the elastic constants of the film results in a positive change, which behaves differently when compared to the mass effect and acoustoelectric effect. Equation (1) shows a positive frequency response occurs as the elastic effect of the sensitive layer significantly increases and exceeds the change in mass and the acoustoelectric effect. All three effects were contributed to the frequency shift; however, it was not able to quantify the contribution for each in this system. Among those three effects, the elastic effect dominated the sensing response. Therefore, Figure 5 indicates that the modification of the elastic effect of the sensitive layer increased the oscillation frequency during exposure to NO gas.

Figure 6 shows the frequency shifts of the SAW sensor coated with a $\mathrm{Cu}^{2+} / \mathrm{PANI} / \mathrm{WO}_{3}$ sensitive layer at NO concentrations ranging from $1 \mathrm{ppb}$ to $200 \mathrm{ppb}$ in dry nitrogen. The number of adsorbed NO molecules decreased as the NO concentration decreased, and therefore, the corresponding frequency shifts decreased. At a NO concentration of $1 \mathrm{ppb}$, a signal with a frequency shift of $4.3 \mathrm{ppm}$ and a signal-to-noise ratio of 17 was observed. The sensitivity of an SAW sensor is defined as the change in the frequency of the sensor in response to a change in NO concentration. The sensitivity of the sensor to the NO concentration is roughly linear in a logarithmic coordinate system.

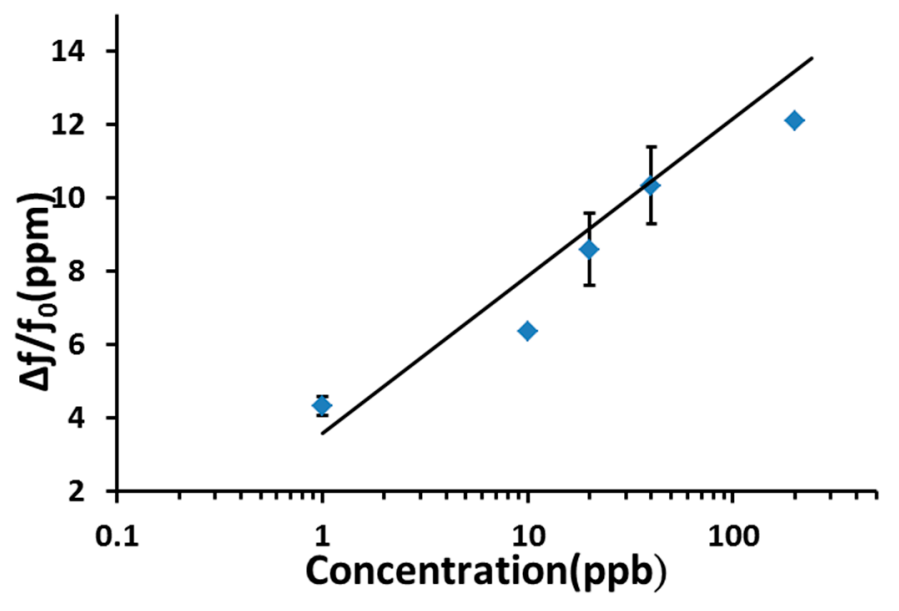

Figure 6. Frequency shifts of the sensor in response to various NO concentrations ranging from $1 \mathrm{ppb}$ to $200 \mathrm{ppb}$ using dry nitrogen as carrier gas at room temperature. 
The $\mathrm{Cu}^{2+} / \mathrm{PANI} / \mathrm{WO}_{3}$ sensitive film was a p-type semiconductor measured by Hall effect measurement in this study. We also examined the NO gas sensing behavior of an SAW sensor in response to impedance changes. We observed that apparent resistance changes occurred at resonant frequency after introduction of the gas. Therefore, the impedance measurement was carried out at the resonant frequency in this study. The response is calculated as $\Delta R / R_{0}=\left(R-R_{0}\right) / R_{0}$, where $R$ is the sensor resistance in presence of $\mathrm{NO}$ in dry nitrogen, and $\mathrm{R}_{\mathrm{o}}$ is the initial resistance of the sensor in dry nitrogen at the resonant frequency in each case. As shown in Figure 7, a decrease in resistance occurred upon exposure to NO, and the response was reversible. Figure 8 shows that the resistance changes increased according to the concentration of NO in the range of 1-100 ppb. The resistance change became gradually saturated after an NO concentration of $70 \mathrm{ppb}$. The resistance of p-type semiconductors decreases when they are exposed to oxidizing gases [30,31]. Because the $\mathrm{Cu}^{2+} / \mathrm{PANI} / \mathrm{WO}_{3}$ sensitive layer was a p-type semiconductor, the resistance decreased when it was exposed to a NO atmosphere. Copper is a typical catalyst applied in selective catalytic reduction reactions, and oxygen was absented in the sensing system of this study. The reduction reaction to the NO gas occurred on the surface of the sensitive layer, and the electrons were extracted from the sensitive layer. Nitric oxide might be reduced by the sensing membrane and it might be reduced into nitrogen and water. Consequently, the resistance decreased because of the increase of the carrier concentration in the sensitive layer, as shown in Figure 7. The proposed mechanism was shown in the following Figure 9.

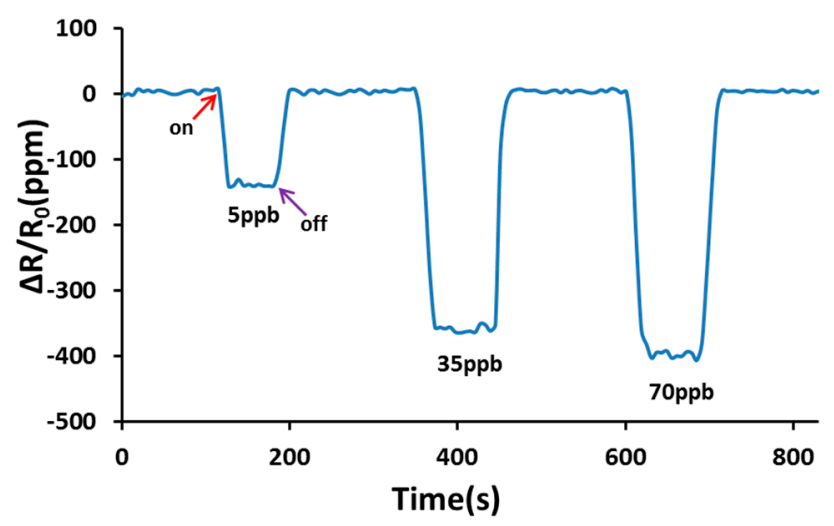

Figure 7. Resistance changes of the sensor at various NO concentrations using dry nitrogen as carrier gas at room temperature.

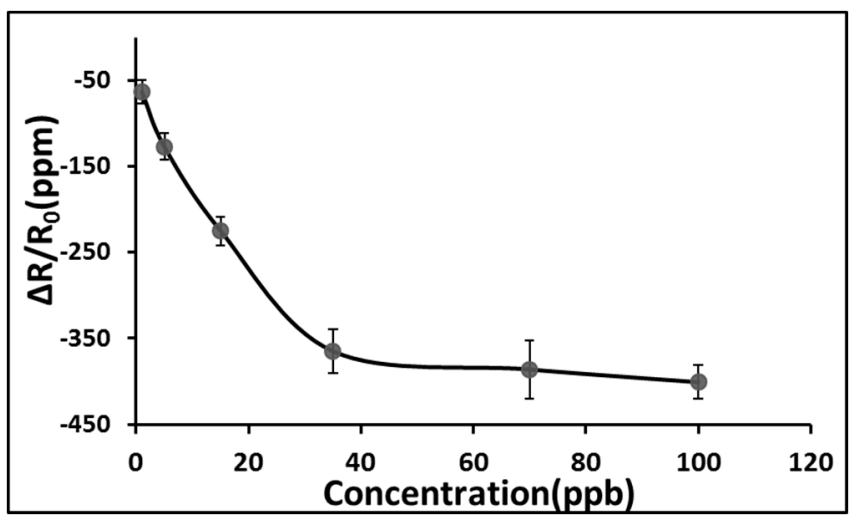

Figure 8. Resistance changes of the sensor at various NO concentrations using dry nitrogen as carrier gas at room temperature. 


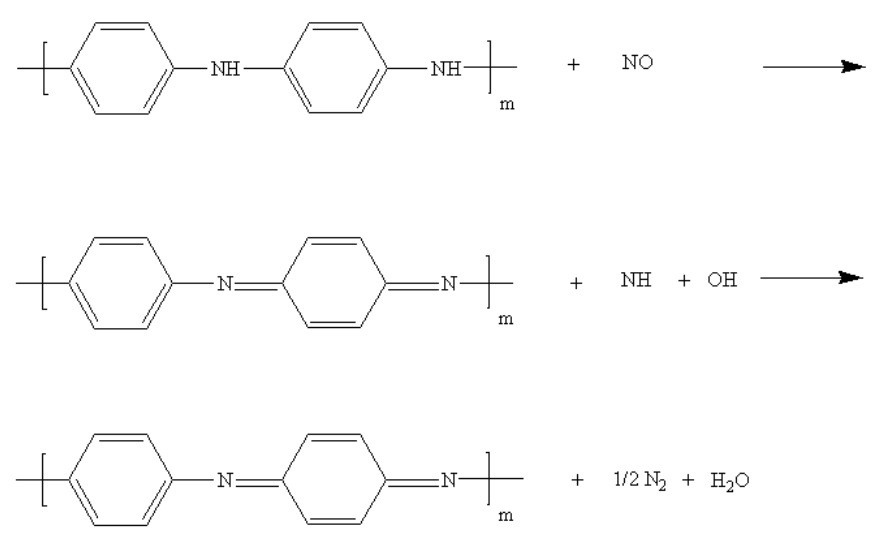

Figure 9. The proposed sensing mechanism.

Figure 10 shows the sensor response to an NO concentration of $10 \mathrm{ppb}$ in three cycles. The frequency shift was approximately $6.4 \mathrm{ppm}$ in each cycle. The repeated extent of the frequency response of the $\mathrm{SAW}$ sensor coated with a $\mathrm{Cu}^{2+} / \mathrm{PANI} / \mathrm{WO}_{3}$ sensitive layer was $92 \%$ after 27 days.

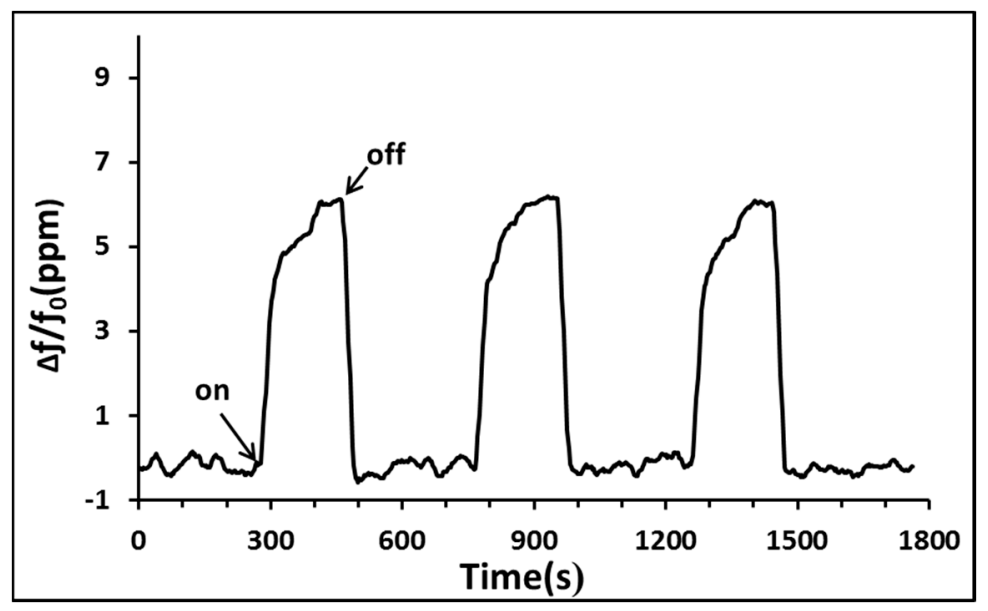

Figure 10. Frequency changes of the sensor at an NO concentration of $10 \mathrm{ppb}$ in three gas on/off cycles using dry nitrogen as carrier gas at room temperature.

Thus, the frequency response exhibited high repeatability and long-term stability. The response time of the sensor was calculated as the time required to reach $90 \%$ of the saturation value upon exposure to the NO gas; the recovery time was defined as the time required by the sensor to recover $90 \%$ of its saturation value after the flow of NO gas was discontinued. When the sensor was exposed to NO, an increase in frequency was observed. Figure 10 shows that the sensor responded to NO at $10 \mathrm{ppb}$, exhibiting a response time of $97 \mathrm{~s}$. After NO gas flow was discontinued and the test chamber was purged with dry nitrogen, the frequency returned to its original value; the measured recovery time was $37 \mathrm{~s}$.

Figure 11 illustrates the response of the SAW sensor coated with a $\mathrm{Cu}^{2+} / \mathrm{PANI} / \mathrm{WO}_{3}$ sensitive layer to $\mathrm{NO}$ gas at $20 \mathrm{ppb}, \mathrm{O}_{2}$ gas at $150 \mathrm{ppm}, \mathrm{NH}_{3}$ gas at $30 \mathrm{ppm}$, and $\mathrm{CO}_{2}$ gas at $55 \mathrm{ppm}$. The sensitivity is defined as the ratio of frequency shift to species concentration under the same gas flow rate and temperature. The gases did not affect the SAW NO sensor at the indicated concentrations. Thus, these results suggest that interference effects, such as those produced by $\mathrm{CO}_{2}$ and $\mathrm{NH}_{3}$, are negligible during the detection of NO at parts-per-billion levels in dry nitrogen. 


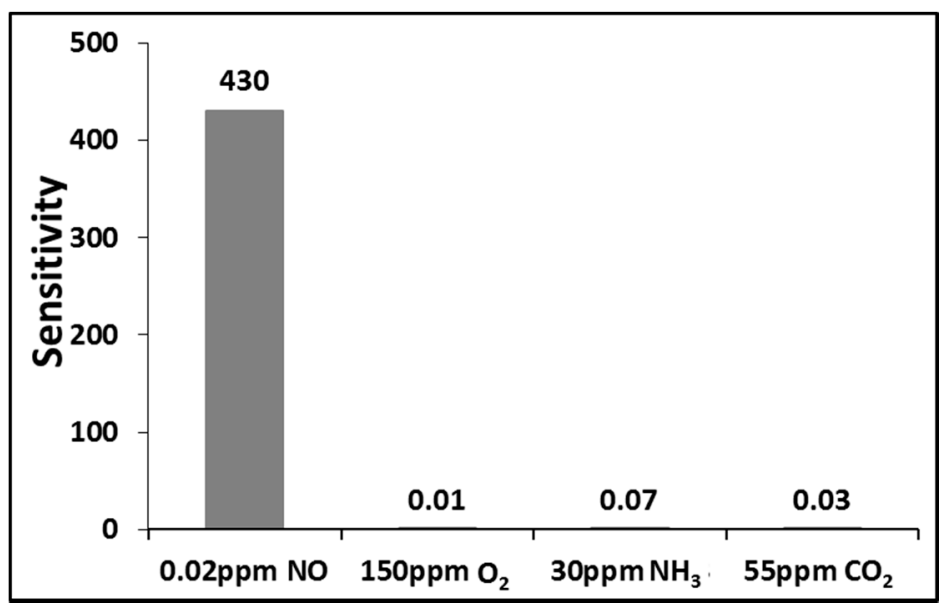

Figure 11. The responses of the sensor to $\mathrm{NO}$ gas at $20 \mathrm{ppb}, \mathrm{O}_{2}$ gas at $150 \mathrm{ppm}, \mathrm{NH}_{3}$ gas at $30 \mathrm{ppm}$, and $\mathrm{CO}_{2}$ gas at $55 \mathrm{ppm}$.

The sensor performance has also been investigated in an atmosphere of dry air to evaluate the influence of oxygen on its response. The frequency shift to 40 ppb of NO is 9.9 ppm in dry nitrogen and $2.1 \mathrm{ppm}$ in dry air, respectively. The frequency shift to $10 \mathrm{ppb}$ of NO is $6.1 \mathrm{ppm}$ in dry nitrogen and $0.8 \mathrm{ppm}$ in dry air, respectively. It is quite clear that the sensor response is lower.

\section{Conclusions}

The results indicated that an SAW sensor coated with a $\mathrm{Cu}^{2+} / \mathrm{PANI} / \mathrm{WO}_{3}$ sensitive layer exhibited high sensitivity, reversibility, repeatability, selectivity, and stability in detecting NO in dry nitrogen. At an NO concentration of $1 \mathrm{ppb}$ in dry nitrogen, a signal with a frequency shift of $4.3 \mathrm{ppm}$ and a signal-to-noise ratio of 17 was observed. The response and recovery times were $97 \mathrm{~s}$ and $37 \mathrm{~s}$, respectively, at an $\mathrm{NO}$ concentration of $10 \mathrm{ppb}$ in dry nitrogen.

Although $\mathrm{NO}$ easily oxidizes and becomes $\mathrm{NO}_{2}$ through a reaction with $\mathrm{O}_{2}$ in a typical environment, the $\mathrm{NO}$ and $\mathrm{N}_{2}$ gases were mainly responsible for the changes in frequency and resistance in this study because of the isolation from oxygen that the controlled chambers provided. Our preliminary findings are a promising starting point to investigate $\mathrm{Cu}^{2+} / \mathrm{PANI} / \mathrm{WO}_{3}$ as sensing layer for $\mathrm{NO}$ gas sensing at room temperature in dry nitrogen. Further improvements of this device will be focused on optimizing the doping concentration in order to reach that the sensor will function in air and minimize the effect of environmental humidity changes on the sensor performance.

\section{Acknowledgments}

The authors thank the Ministry of Science and Technology, Taiwan, for partially supporting this research under Contract No. NSC 102-2221-E-214-003-MY3-1.

\section{Author Contributions}

All authors contributed extensively to the work presented in this paper. Shih-Han Wang designed the sensitive layer and Chi-Yen Shen conceived this study. Jian-Ming Su conducted the sensor analysis and gathered the data. Shiang-Wen Chang synthesized the sensing material. 


\section{Conflicts of Interest}

The authors declare no conflict of interest.

\section{References}

1. Wartelle, C.; Pereira Rodrigues, N.; Koudelka-Hep, M.; Bedioui, F. Amperometric fluidic microchip array sensing device for nitric oxide determination in solution. Mater. Sci. Eng. C 2006, 26, 534-537.

2. Kim, J.W.; Oh, E.G.; Cha, G.Y.; Jeong, S.H.; Huh, J.S. NO Sensing Characteristics of ZnO Nanorod Prepared by Ultrasound Radiation Method. In Proceedings of the 5th IEEE International Conference on Sensors, Daegu, South Korea, 22-25 October 2006; pp. 239-242.

3. Rathgeb, F.; Gauglitz, G. Optical gas sensors in analytical chemistry: Applications, trends and general comments. In Encyclopedia of Analytical Chemistry; Meyers, R.A., Ed.; Wiley: New York, NY, USA, 2000; pp. 2189-2203.

4. Menil, F.; Coillard, V.; Lucat, C. Critical review of nitrogen monoxide sensors for exhaust gases of lean burn engines. Sens. Actuators B 2000, 67, 1-23.

5. Vilar, M.R.; El-Beghdadi, J.; Debontridder, F.; Naaman, R.; Arbel, A.; Ferraria, A.M.; do Rego, A.M. Development of nitric oxide sensor for asthma attack prevention. Mater. Sci. Eng. C 2006, 26, 253-259.

6. Bisgaard, H.; Loland, L.; AnhØj, J. NO in exhaled air of asthmatic children is reduced by the leukotriene receptor antagonist montelukast. Am. J. Respir. Crit. Care Med. 1999, 160, 1227-1231.

7. Smith, A.D.; Taylor, D.R. Is exhaled nitric oxide measurement a useful clinical test in asthma. Curr. Opin. Allergy Clin. Immunol. 2005, 5, 49-56.

8. Taylor, D.R.; Pijnenburg, M.W.; Smith, A.D.; Jongste, J.C.D. Exhaled nitric oxide measurements: Clinical application and interpretation. Thorax 2006, 61, 817-827.

9. Bateman, R.M.; Ellis, C.G.; Freeman, D.J. Optimization of nitric oxide chemiluminescence operating conditions for measurement of plasma nitrite and nitrate. Clin. Chem. 2002, 48, 570-573.

10. Mondal, S.P.; Dutta, P.K.; Hunter, G.W.; Ward, B.J.; Laskowski, D.; Dweik, R.A. Development of high sensitivity potentiometric $\mathrm{NO}_{\mathrm{x}}$ sensor and its application to breath analysis. Sens. Actuators B 2011,158, 292-298.

11. Sun, C.; Maduraiveeran, G.; Dutta, P. Nitric oxide sensors using combination of p- and n-type semiconducting oxides and its application for detecting NO in human breath. Sens. Actuators $B$ 2013, 186, 117-125.

12. Zhang, P.S.; Zhang, W.; Gerlach, F.; Ahlborn, K.; Guth, U. Electrochemical investigations on multi-metallic electrodes for amperometric NO gas sensors. Sens. Actuators B 2005, 108, 797-802.

13. Sharma, A.; Tomar, M.; Gupta, V. Improved Response Characteristics of $\mathrm{SnO}_{2}$ Film Based $\mathrm{NO}_{2}$ Gas Sensor with Nanoscaled Metal Oxide Catalysts. In Proceedings of the 14th International Meeting on Chemical Sensors, Nuremberg, Germany, 20-23 May 2012; pp. 702-705.

14. Kukkola, J.; Maklin, J.; Halonen, N.; Kyllonen, T.; Toth, G.; Szabo, M.; Shchukarev, A.; Mikkola, J.P.; Jantunen, H.; Kordas, K. Gas sensors based on anodic tungsten oxide. Sens. Actuators $B$ 2011, 153, 293-300. 
15. Wang, S.H.; Kuo, S.H.; Shen, C.Y. A nitric oxide gas sensor based on Rayleigh surface acoustic wave resonator for room temperature operation. Sens. Actuators B 2011, 156, 668-672.

16. Fu, M.; Li, C.; Lu, P.; Qu, L.; Zhang, M.; Zhou, Y.; Yu, M.; Fang, Y. A review on selective catalytic reduction of $\mathrm{NO}_{\mathrm{x}}$ by supported catalysts at $100-300{ }^{\circ} \mathrm{C}-$ Catalysts, mechanism, kinetics. Catal. Sci. Technol. 2014, 4, 14-25.

17. Fox, C.G.; John Alder, F. Surface acoustic wave sensors for atmospheric gas monitoring. A review. Analyst 1989, 114, 997-1004.

18. Drafts, B. Acoustic wave technology sensors. IEEE Trans. Microw. Theory Tech. 2001, 49, 795-802.

19. Thompson, M.; Stone, D.C. Surface-Launched Acoustic Wave Sensors: Chemical Sensing and Thin Film Characterization; Wiley: New York, NY, USA, 1997.

20. Shen, C.Y.; Hsu, C.L.; Su, M.Y.; Tsai, R.T.; Wang, S.H. Propagation characteristics of surface acoustic wave and properties of gas sensors on quartz. In IUTAM Symposium on Recent Advances of Acoustic Waves in Solids; Springer: London, UK, 2010; Volume 26, pp. 293-302.

21. Wang, S.H.; Chou, T.C.; Liu, C.C. Nano-crystalline tungsten oxide $\mathrm{NO}_{2}$ sensor. Sens. Actuators $B$ 2003, 94, 343-351.

22. Shen, C.Y.; Huang, H.M.; Wang, S.H.; Chiu, Y.C. Room temperature detection properties of a surface acoustic wave gas sensor with $\mathrm{Cu}^{2+} / \mathrm{PANI} / \mathrm{SnO}_{2}$ nanocomposite thin film to nitric oxide. Appl. Mech. Mater. 2013, 312, 732-735.

23. Schulz, M.B.; Matsinger, B.J.; Holland, M.G. Temperature dependence of surface acoustic wave velocity on $\alpha$ quartz. J. Appl. Phy. 1970, 7, 2755-2765.

24. Sinha, B.K.; Tiersten, H.F. On the temperature dependence of the velocity of surface waves in quartz. J. Appl. Phys. 1980, 51, 4659-4665.

25. Henry-Briot, E.; Ballandras, S.; Marianneau, G.; Martin, G. Influence of metal thickness on phase velocity and thermal sensitivity of SAW devices. IEEE Trans. Ultrason. Ferroelectr. Freq. Control 2001, 48, 538-546.

26. Grate, J.W.; Stephen, J.M.; Richard, M.W. Acoustic wave microsensors. Anal. Chem 1993, 65, 940A-948A.

27. Montress, G.K.; Parker, T.E.; Andrea, D. Review of SAW Oscillator Performance. In Proceedings of the IEEE Ultrasonics Symposium, Cannes, France, 31 October-3 November 1994; pp. 43-54.

28. Ricco A.J. SAW chemical sensors, an expanding role with global impact. Electrochem. Soc. Interface 1994, 3, 38-45.

29. Wohltjen, H. Mechanism of operation and design consideration for surface acoustic wave device vapor sensor. Sens. Actuators 1984, 5, 307-325.

30. Ray, S.; Gupta, P.S.; Singh, G. Electrical and optical properties of sol-gel prepared Pd-doped $\mathrm{SnO}_{2}$ thin films: Effect of multiple layers and its use as room temperature methane gas sensor. J. Ovonic Res. 2010, 6, 23-34.

31. Geng, L.; Zhao, Y.; Huang, X.; Wang, S.; Zhang, S.; Wu, S. Characterization and gas sensitivity study of polyaniline/ $\mathrm{SnO}_{2}$ hybrid material prepared by hydrothermal route. Sens. Actuators $B$ 2007, 120, 568-572.

(C) 2015 by the authors; licensee MDPI, Basel, Switzerland. This article is an open access article distributed under the terms and conditions of the Creative Commons Attribution license (http://creativecommons.org/licenses/by/4.0/). 